\title{
Erratum to: Walters, Bradley B., with Bonnie J. McCay, Paige West, and Susan Lees (eds): Against the Grain: The Vayda Tradition in Human Ecology and Ecological Anthropology
}

\section{Constanza Ocampo-Raeder}

Published online: 28 July 2010

(C) Springer Science+Business Media, LLC 2010

\section{Erratum to: Hum Ecol}

DOI 10.1007/s10745-010-9315-5

The original version of this article unfortunately contained a mistake.

The word "casual" should be "causal" in the article seen at pages 468 (Column 1, Lines 17, 35; Column 2, 5th line from bottom) and 469 (Column 1, Line 24). 